\title{
Introduction to the Inaugural Issue of International Journal of Community Well-Being
}

\author{
Rhonda Phillips ${ }^{1} \cdot$ Seung Jong Lee ${ }^{2}$
}

Published online: 2 November 2018

(C) Springer Nature Switzerland AG 2018

Welcome to the inaugural issue of International Journal of Community Well-Being, published by Springer in collaboration with the Global Community Institute housed in Korea. This organization is the next generation of the research collaborative, Community Well-Being Research Center, bringing together scholars with interests in wellbeing from around the globe. This journal advances the knowledge and practice of community well-being as an interdisciplinary broad conception of human and societal well-being. The focus is predominately on communities of place and interest within geographic or societal spaces concerning social, economic, cultural, social, environmental or political conditions and impacts on societal and social well-being. It provides an outlet for excellent scholarship from a multitude of disciplines - including but not limited to community development, geography, urban and regional planning, economic development, public administration, regional studies, sociology, community learning and education, psychology and health - concerned with community well-being that promotes understanding of its multidimensional aspects.

There does not yet exist one definition that clearly defines community well-being, a reflection of the interconnectedness, complexity, and nuances inherent in its study and application. We think it is embedded with multidimensional values and domains that influence people and where they live - their communities, across a spectrum of perspectives and outcomes. It is our hope that others will join us in seeking theoretical and applied constructs in scholarship and practice in this area of study. We seek to publish research that combines community well-being with issues facing our towns, cities and regions. It explores the collective aspects of communities and regions and how individual well-being is related to the context of societal well-being.

As a new journal, our mission is to encourage interest in community well-being as a research, practice, and policy focus. For several years now, more publications in this

Rhonda Phillips

rphillips@purdue.edu

1 Purdue University, West Lafayette, IN, USA

2 Seoul National University, Seoul, South Korea 
area of inquiry have appeared in the literature, ranging from empirical, quantitative, qualitative, to cases and analyses of policies and programs. We seek to provide an outlet for a variety of types of research, including original research articles, overview articles, perspective articles, and cases. We are delighted that Meg Holden of Simon Fraser University is serving on our editorial team as Reviews and Special Issues Editor. Please take a moment and read her introduction to the Reviews Section; it is both inspiring and informative with the intent of fostering interest in sharing analyses and insights on books, policies, and programs connected to community well-being.

It also is a pleasure to introduce our editorial board (see listing of members on the inside cover). We have invited scholars from around the globe to join us in launching a new era of well-being research centered on communities. Bringing together diverse perspectives from across numerous disciplines and approaches, our Editorial Board will be instrumental to the journal's success as will be our Managing Editor, Jason Ware of Purdue University.

We invite you to explore the articles contained within Volume 1, Number 1, along with the reviews section. Each has been carefully selected to provide a variety of topics on which research on community well-being has been conducted. From public administration and policy to adult learning contexts, these articles represent a panoply of disciplines and approaches to research. With the commencement of Volume 1, we have invited "thought leaders" - influential researchers in community well-being to provide an opening essay for each issue. M. Joseph Sirgy, a noted scholar in quality of life and well-being, shares some thoughts on indicators as a means of measuring or assessing community well-being. Bringing together perspectives gleaned from years of research on indicators, his essay provides an essential foundation for continued work as the area of study continues to gain momentum and interest. 